\title{
Twenty-one years of arq
}

This issue concludes the twenty-first volume of arq. The age of twenty-one traditionally represents coming of age in most Western cultures. So we've taken the opportunity to reflect, in this issue, on changes in architectural research since the first arq was published. We've asked various members of our distinguished Editorial Board either to look back on the last twenty-one years, or to speculate about the next twenty-one years of architectural research, under our customary thematic headings: 'design', 'criticism', 'theory', 'history', 'environmental design', 'digital', 'materials', 'urbanism', 'practice', 'education', and 'research'. Board members' insightful reflections provide most of the articles collected here. We also asked two Board members to review the book from the last twenty-one years they found most influential. And we solicited a handful of additional contributions concerning some of the early and continuing preoccupations of arq - like research-by-design, and practice-based research - to review methodologies and fields that have, at least to some extent, come of age in the pages of arq.

Peter Carolin, the journal's Founding Editor, reflects here (pp.315-320) on the motivations for setting up arq, ostensibly prompted by the first government-led 'Research Assessment Exercise' held in UK universities, but also rooted in longer cultures of research for-, into- and through-design (to use Christopher Frayling's tripartite categorisation, published shortly before the first arq). Carolin's article leads a group of articles under the thematic heading of 'research'. These include Joshua D. Lee and Steven A. Moore's coding of arq's preoccupations (pp. 321-327), and Rowena Hay, Neal Shasore, and Flora Samuel's study of foundational research strategy at the Royal Institute of British Architects (pp. 328-337). These studies are supplemented by Francisco Brown's survey of specialist research units in four architecture studios in New York (pp. 393-396).

Broader reflections on research in our multi- and inter-disciplinary field include: Peggy Deamer's questioning of whether current definitions of 'research' are stifling 'ideas' relevant to the discipline (pp. 344-346); Silke Kapp's consideration of 'central' and 'peripheral' positions in architecture in relation to globalised scientific and economic methods (pp. 311-314); Jianfei Zhu's championing of architectural research 
as a field of relations spreading locally and trans-locally across a vast geography (pp. 383-386); Michael J. Ostwald's longitudinal analysis of research themes in the last twenty-one years of digital research (pp. 351-358); and Timothy Hyde's proposal that architectural history should forge bigger ambitions, of broader scope and more varied techniques (pp. 347-35o). Jonathan Sergison, meanwhile, reviews the 'search' in Sergison Bates's practice-based 'research' (pp.298-309).

This issue presents a collection of thought-provoking and informed reflections on current, past, and future directions and priorities in architectural research. The articles represent original, significant and rigorous work, valuable to both practitioners and academics, mirroring the contents of arq for the last twenty-one years and, we hope, the next twenty-one.

THE EDITORS 


\section{architectural research quarterly}

\section{Subscribe now for 2018}

Innovative in conception, unique in breadth and generously illustrated, this pace-setting quarterly publication from Cambridge University Press links, on a global scale, the worlds of architectural practice and research. arq regularly includes extensive peer-reviewed sections on design, history, theory, construction, environmental design, education and practice - as well as structures, urbanism and documents. These are supplemented by letters, reports, reviews and an annual index. Each issue opens with a leader and closes with insight, a personal end-piece. In its eighteen year history, arq has published work from all over the world: from Chile to Sweden and from Japan to the Netherlands - with a strong representation from the United

Kingdom and United States. arq, like architecture itself, is all-embracing and written by and for both practitioners and academics. It provides an outlet for all those who wish to disseminate their work to an international audience.
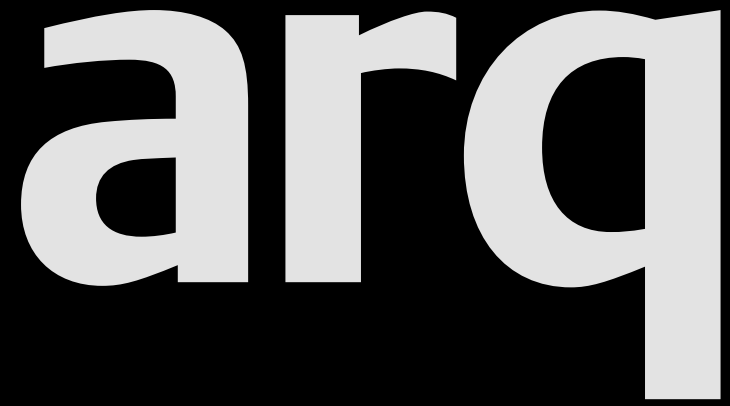

Please enter my subscription to arq: architectural research quarterly, volume 21, 2017

$E_{312} / \$ 524$ institutions print and electronic

$E_{3} 8 / \$ 63$ students print only

$£_{53} / \$ 81$ individuals print only

EU residents only. VAT may be payable at your local rate if not registered.

Our VAT registration number: GB 214141614 If registered, your VAT registration no:

Total subscription payment $€ / \$$ Eu residents only, if not registered add VAT at appropriate rate ${ }^{£}$

Canadian residents, add 7\% GST \$ Total $\mathbf{E} / \mathbf{S}$

Name

Address

Payment enclosed

Cheque in sterling or US dollars

(payable to Cambridge University Press)

Credit Card - VISA | MasterCard | American Express (delete where applicable)

Card no

Expiry date

Signature

Photocopy this page and send your order to:

Journals Customer Services, Cambridge University Press, UPH, Shaftesbury Road, Cambridge, СB2 8BS, UK

$\mathrm{T}+44(0) 1223326070$

$\mathrm{F}+44(0) 1223315052$

E journals@cambridge.org

or in USA, Canada and Mexico send to:

Cambridge University Press, 1 Liberty Plaza,

Floor 20, New York, NY 10006, USA

T (914) 9379600

F (914) 9374712

E journals_subscriptions@cup.org 